\title{
Non classic presentations of a genetic mutation typically associated with transient neonatal diabetes
}

\author{
Janani Devaraja¹, Charlotte Elder and Adrian Scott² \\ 1Sheffield Children's Hospital NHS Trust and 2Academic Directorate of Diabetes \& Endocrinology at Sheffield \\ Teaching Hospital NHS Trust, Sheffield, UK
}

Correspondence should be addressed to A Scott

Email

adrian.scott5@nhs.net

\section{Summary}

This case report describes a family pedigree of a mother and her children with an E227K mutation in the KCNJ11 gene. People with this particular gene mutation typically present with transient neonatal diabetes; with more than half the cohort relapsing into permanent diabetes in adolescence or early adulthood. However, the mother developed diabetes as an adolescent and thus was initially diagnosed as having Type 1 Diabetes. All her children have inherited the same genetic mutation but with differing presentations. Her second, third and fourth child presented with transient neonatal diabetes which remitted at varying times. Her first child is 16 years old but had not developed diabetes at the time of writing. The KCNJ11 gene codes for the KIR6.2 subunit of the $\mathrm{K}_{\text {ATP }}$ channels of the pancreatic beta cells. Mutations in this gene limit insulin release from beta cells despite high blood glucose concentrations. Most people with diabetes caused by this genetic mutation can be successfully managed with glibenclamide. Learning of the genetic mutation changed the therapeutic approach to the mother's diabetes and enabled rapid diagnosis for her children. Through this family, we identified that an identical genetic mutation does not necessarily lead to the same diabetic phenotype. We recommend clinicians to consider screening for this gene in their patients whom MODY is suspected; especially in those presenting before the age of 25 who remain C-peptide positive.

\section{Learning points:}

- $\mathrm{K}_{\text {ATP }}$ channel closure in pancreatic beta cells is a critical step in stimulating insulin release. Mutations in the KIR6.2 subunit can result in the $\mathrm{K}_{\text {ATP }}$ channels remaining open, limiting insulin release.

- People with KCNJ11 mutations may not present with neonatal diabetes as the age of presentation of diabetes can be highly variable.

- Most affected individuals can be treated successfully with glibenclamide, which closes the $\mathrm{K}_{\text {ATP }}$ channels via an independent mechanism.

- All first degree relatives of the index case should be offered genetic testing, including asymptomatic individuals. Offspring of affected individuals should be monitored for neonatal diabetes from birth.

- Affected individuals will require long-term follow-up as there is a high risk of recurrence in later life.

\section{Background}

Neonatal diabetes (ND) is a form of monogenic diabetes occurring before 6 months of age. ND presents with similar features to Type 1 Diabetes (hyperglycaemia, dehydration, weight loss and ketoacidosis) $(1,2,3)$. Low insulin $\mathrm{C}$ peptide levels and absence of antibodies typically associated with Type 1 Diabetes are found 
on investigation $(1,2)$. Chromosome 6 anomalies and mutations in the KCNJ11 and ABCC 8 genes on chromosome 11 can cause transient and permanent ND $(1,2)$. Transient ND represents approximately half of ND cases. The diabetes tends to remit spontaneously, usually within 4 to 60 weeks of onset (2). Approximately half the cohort will relapse around adolescence and young adulthood (2).

Mutations in the KCNJ11 and ABCC8 genes usually occur de novo but then lead to an inherited genetic susceptibility (1). The KCNJ11 gene encodes for the KIR6.2 subunit of the $\mathrm{K}_{\text {ATP }}$ channel (ATP sensitive potassium channel) of the pancreatic beta cells (1). The $\mathrm{K}_{\mathrm{ATP}}$ of the beta cell is a complex of four pore-forming KIR6.2 subunits and four regulatory SUR1 (sulphonylurea receptor 1) subunits (4). The SUR1 subunit is encoded by the ABCC8 gene. In an unaffected individual, an increase in blood glucose concentration leads to an increase in glucose metabolism in beta cells (3). This causes the formation of ATP molecules which close the $\mathrm{K}_{\mathrm{ATP}}$ channels (5). Closure of these channels leads to membrane depolarization which opens the voltage-gated calcium channels. The subsequent calcium influx into the beta cells stimulates insulin release $(3,5)$. The closure of the $\mathrm{K}_{\mathrm{ATP}}$ channels is the central step in the pathway of insulin release. E227K mutation in the KCNJ11 gene leads to the replacement of lysine with glutamic acid at position 227 in the $\mathrm{K}_{\mathrm{ATP}}$ channels (1). This mutation causes the KIR6.2 subunits to be less sensitive to ATP. The $\mathrm{K}_{\mathrm{ATP}}$ channels therefore remain open causing hyperpolarization of the plasma membrane $(3,5)$. Thus calcium channels remain closed, preventing insulin release (3).

This case highlights the different diabetic phenotypes within family members carrying the same genetic mutation. The family members in this case report have a heterozygous E227K mutation in the KCNJ11 gene which is typically associated with transient ND. However the mother did not develop diabetes until the age of 14 . All of her children have inherited the same mutation, yet manifest with different phenotypes. This case report demonstrates that $\mathrm{E} 227 \mathrm{~K}$ mutation in the KCNJ11 gene is associated with a variable age of presentation.

\section{Case presentation}

The mother was diagnosed with Type 1 diabetes at 14 years of age. There was no history suggestive of diabetic symptoms as a neonate. No other older family members have diabetes. She frequently omitted insulin, failed to attend multiple appointments and was lost to follow-up.
She represented to adult diabetes services at 30 years of age, after the birth of her second child. She was referred to the ophthalmologist following a vitreous haemorrhage. She reported not having taken insulin for 2 years. Her HbA1c was $140.4 \mathrm{mmol} / \mathrm{mol}$ (15\%) and blood glucose level was $54 \mathrm{mmol} / \mathrm{L}$. Unusually there were no ketones on blood testing, and her plasma insulin $\mathrm{C}$ peptide level was $430 \mathrm{pmol} / \mathrm{L}$. This, coupled with the history of transient diabetes in her second child, led to the suspicion of monogenic diabetes. Genetic testing was undertaken and she was diagnosed in 2009. Insulin was stopped and she was switched to oral glibenclamide after genetic diagnosis was confirmed. Her HbA1C improved to 44 $\mathrm{mmol} / \mathrm{mol}(6.2 \%)$ within a year. However, her previously poor diabetic control had already led to significant health complications. Three of her four children were born prematurely because of poor health secondary to diabetic nephropathy (Figure 1).

The first child (C1) was born at 37 weeks of gestational age. She did not develop ND. She is in good health and has no symptoms suggestive of diabetes. She had genetic testing performed as an adolescent.

The second child (C2) was born at $33+5$ weeks of gestational age. He developed ND on day 1 of life and commenced insulin. He was on twice daily intermediate acting insulin for 7 months until his diabetes remitted spontaneously and was discharged from paediatric diabetes

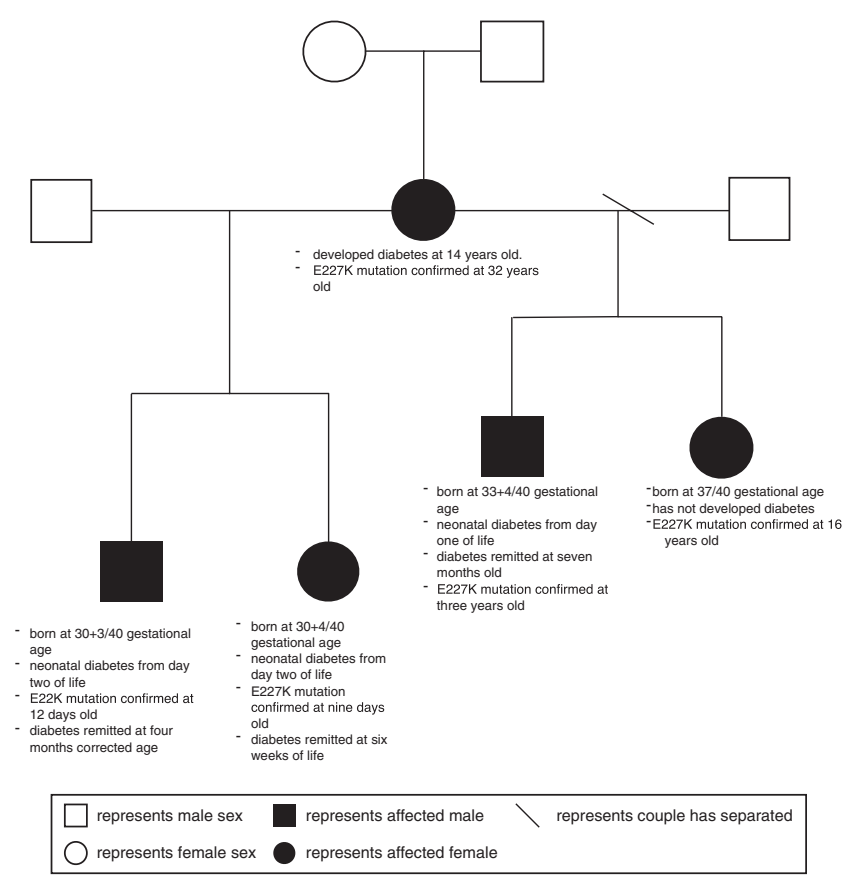

Figure 1

Schematic presentation of the family pedigree illustrated in this case. 
services. The mother's genetic mutation was identified when he was 3 years old. Attempts were made to bring him back for follow-up but were unsuccessful until he was 13 years old, following the birth of the fourth child.

The third child (C3) was born at $30+4$ weeks of gestational age. She developed ND and commenced insulin on day 2 of life. She had rapid genetic testing and started glibenclamide on day 9 of life. She stopped insulin the following day. Her diabetes remitted at 6 weeks of age. Attempts to then follow-up the child were unsuccessful until she was 3 years old.

The fourth child (C4) was born at $30+3$ weeks gestational age. He developed ND and commenced insulin on day 2 of life. He had rapid genetic testing, but due to his poor condition at birth and difficulty in obtaining glibenclamide, he commenced glibenclamide on day 14 of life. He remained on glibenclamide until 4 months of corrected age.

\section{Investigation}

Genetic testing confirmed a heterozygous E227K mutation in the KCNJ11 gene.

\section{Treatment}

The mother is taking an oral glibenclamide dose of $15 \mathrm{mg}$ once daily. She had been off insulin until recently. C3 and C4's neonatal diabetes were successfully managed on oral glibenclamide until they remitted. None of the children are currently on medication.

\section{Outcome and follow-up}

Since the birth of her fourth child, the mother has reengaged with adult diabetes services. Her HbA1C improved to $44 \mathrm{mmol} / \mathrm{mol}$ (6.2\%) within 1 year of switching to glibenclamide. However, her previously poor glycaemic control had led to significant diabetic retinopathy and maculopathy and nephropathy. She required laser therapy and vitrectomy. Her diabetic nephropathy necessitated 3 years of dialysis before a renal transplant in 2017. She has subsequently developed antibody mediated rejection of her transplanted kidney, necessitating high dose steroids and immunoglobulins. This has led to a steroid-induced element to her diabetes, and she has been commenced on Levemir insulin.

All her children have had genetic testing and have the same mutation. $\mathrm{C} 1$ has yet to develop diabetes and C2, C3 and C4 remain in remission. C1, C2 and C3's recent
HbA1C and fasting blood glucose level were normal. However, the risk of diabetes recurrence is high and we cannot predict when they will relapse. They will all receive annual follow-up, with monitoring of blood glucose and HbA1c. They will also undergo genetic counselling when age-appropriate, as they have a $50 \%$ chance of passing the gene to their offspring(s).

\section{Discussion}

Many of the genetic mutations causing monogenic diabetes were not discovered when the mother was diagnosed with Type 1 diabetes. The activating mutations in the gene encoding for the KIR6.2 subunit (KCNJ11 gene) were first described in 2004 (1). However the mother and $\mathrm{C} 1$ were unusual in not developing ND, despite carrying that particular genetic mutation. The misdiagnosis and poor compliance with insulin led to the mother developing multiple diabetic complications. However, the correct diagnosis has proven beneficial for two of her children, as it enabled them to receive rapid diagnoses and an early start on sulphonylurea therapy. They will receive monitoring to enable early detection and treatment of the diabetes relapse, thus hopefully preventing any diabetic complications.

There have been several cases of people with KCNJ11 mutations who did not develop ND but developed diabetes later in life (6, 7, 8; Table 1). Abbasi et al. (6) found $\mathrm{E} 227 \mathrm{~K}$ mutation within the KCNJ11 gene in three family members, where the age of onset of diabetes was 40 days of age, 2 years and 15 years of age, respectively. Støy et al. (7) found a family where an autosomal dominant transmission of a E227K mutation was identified; but only one family member had ND and the rest had developed diabetes in their twenties. Bonnefond et al. (8) identified a KCNJ11 mutation in several family members who developed diabetes in their adolescence (Table 1), but none had developed ND.

This and other case studies $(6,7,8)$ therefore show a variable age of timing of diabetic symptoms with the same genetic mutation. Testing for KCNJ11 mutations is done in all infants who are diagnosed with diabetes at less than 6 months of age. Testing for this mutation is now also part of the full 39 gene MaturityOnset Diabetes of the Young (MODY) panel (9). We recommend that clinicians consider screening for this genetic mutation when MODY is considered, especially if GCK, HNF1A and HNF4A gene testing is negative. 
Table 1 The age of onset of diabetes and type of KCNJ11 mutation detected in the families studied by Abbasi et al. (6), Støy et al. (7) and Bonnefond et al. (8).

\begin{tabular}{|c|c|c|c|}
\hline Case series & $\begin{array}{l}\text { Proband and } \\
\text { relationship to } \\
\text { proband }\end{array}$ & $\begin{array}{l}\text { Age of onset } \\
\text { of diabetes }\end{array}$ & $\begin{array}{l}\text { Type of } \\
\text { mutation in } \\
\text { KCNJ11 gene } \\
\end{array}$ \\
\hline \multirow[t]{4}{*}{ Abbasi et al. (6) } & & & E227K \\
\hline & Proband & 40 days & \\
\hline & Proband's sibling & 2 years & \\
\hline & Proband's father & 15 years & \\
\hline \multirow[t]{3}{*}{ Støy et al. (7) } & & & $\mathrm{H} 46 \mathrm{Y}$ \\
\hline & Proband & N/M & \\
\hline & Proband' mother & 12 days & \\
\hline Støy et al. (7) & Proband & $\mathrm{N} / \mathrm{M}$ & V59M \\
\hline Støy et al. (7) & Proband & 25 weeks & V59M \\
\hline Støy et al. (7) & Proband & 4 weeks & R201C \\
\hline Støy et al. (7) & Proband & N/M & R201C \\
\hline Støy et al. (7) & Proband & 3 weeks & R201H \\
\hline Støy et al. (7) & Proband & $\mathrm{N} / \mathrm{M}$ & $\mathrm{R} 201 \mathrm{H}$ \\
\hline Støy et al. (7) & Proband & N/M & R201H \\
\hline Støy et al. (7) & Proband & N/M & $\mathrm{R} 201 \mathrm{H}$ \\
\hline Støy et al. (7) & Proband & N/M & R201H \\
\hline \multirow[t]{3}{*}{ Støy et al. (7) } & & & R201H \\
\hline & Proband & N/M & \\
\hline & Proband's father & N/M & \\
\hline Støy et al. (7) & Proband & N/M & E322K \\
\hline \multirow[t]{2}{*}{ Støy et al. (7) } & & & E227K \\
\hline & $\begin{array}{l}\text { Proband } \\
\text { Proband's father }{ }^{\dagger}\end{array}$ & $\begin{array}{l}5 \text { weeks } \\
\text { In } 20 \text { s }\end{array}$ & \\
\hline \multirow{5}{*}{$\begin{array}{l}\text { Bonnefond } \\
\text { et al. (8) }\end{array}$} & & & E227K \\
\hline & Proband* & 16 years & \\
\hline & Proband's father & 13 years & \\
\hline & $\begin{array}{l}\text { Proband's } \\
\text { grandmother }\end{array}$ & 59 years & \\
\hline & $\begin{array}{l}\text { Proband's distant } \\
\text { relatives }\end{array}$ & $\begin{array}{l}17,20,23 \\
\text { and } 47 \\
\text { years }\end{array}$ & \\
\hline
\end{tabular}

*Proband has two siblings with the same mutation but do not have diabetes (yet). tSeveral other family members with diabetes but did not have genetic testing.

N/M: not mentioned in the article by authors.

The discovery of this genetic mutation and its impact on $\mathrm{K}_{\text {ATP }}$ channels have led to a switch in treatment from insulin to sulphonylureas. Sulphonylureas work by binding to the SUR1 subunits of the $\mathrm{K}_{\mathrm{ATP}}$ channels and closing them via an ATP independent mechanism (5). It has been shown that $90 \%$ of patients who switched to sulphonylureas were able to stop insulin successfully, with a reduction in $\mathrm{HbA1C}$ and sustained improvement in glycaemic control $(5,10)$. There were no severe hypoglycaemic episodes reported, and there was no increase in frequency of mild to moderate hypoglycaemia (9). Their in vitro study demonstrated that sulphonyureas closed more than $75 \%$ of the KATP channels in patients with KCNJ11 mutations (10).

Some Kir 6.2 and SUR1 mutations lead to developmental delay, muscle weakness and/or epilepsy in addition to diabetes. This is known as DEND syndrome (development delay, epilepsy and diabetes) $(1,11)$. It is thought that these specific Kir 6.2 mutations also affect the functioning of $\mathrm{K}_{\mathrm{ATP}}$ channels in the nerves, muscles and brain (10). Patients with these specific genetic mutations who start glibenclamide early could have an improvement in their neurological prognosis (11).

In view of the $90 \%$ success rate, we recommend that affected individuals are trialled on glibenclamide as they may see an improvement in the glycaemic control. They will initially need close monitoring due to the variable timing of spontaneous remission. All first degree relatives of the index case should be considered for genetic counselling and testing for the mutation regardless of age of onset and presence of diabetic symptoms. This will enable early detection of individuals with the genetic mutation but have yet to develop diabetes, allowing for follow-up to prevent diabetic complications. Offspring of affected individuals should be monitored for diabetes from birth, as there is a $50 \%$ chance of inheriting the mutation.

Even after medication is stopped, long-term follow-up is required due to the high risk of recurrence of diabetes. We recommend an annual fasting blood glucose and HbA1C level monitoring. Oral glibenclamide can also be effective in a recurrence.

Declaration of interest

The authors declare that there is no conflict of interest that could be perceived as prejudicing the impartiality of the research reported.

\section{Funding}

This research did not receive any specific grant from any funding agency in the public, commercial or not-for-profit sector.

\section{Patient consent}

Written consent has been obtained from the patient for publication of this article.

\section{Author contribution statement}

J Devaraja and C Elder are part of the paediatric diabetes team who are looking after the children. A Scott is the mother's diabetes consultant. J Devaraja wrote the manuscript. A Scott and C Elder reviewed the manuscript and contributed to the discussion. 


\section{Acknowledgements}

The authors would like to acknowledge Prof Sian Ellard and Prof Andrew Hattersly from Pennisula Medical School, Exeter for undertaking the genetic studies that led to the genetic diagnosis for this family. The authors would like to extend their gratitude to the adult diabetic team at Sheffield Teaching Hospital and to the paediatric diabetic team at Sheffield Children Hospital for looking after this family.

\section{References}

1 Gloyn AL, Pearson ER, Antcliff JF, Proks P, Bruining GJ, Slingerland AS, Howard N, Srinivasan S, Silva JM, Molnes J, et al. Activating mutations in the gene encoding the ATP sensitive potassium channel subunit Kir 6.2 and permanent neonatal diabetes. New England Journal of Medicine 2004350 1838-1849. (https://doi. org/10.1056/NEJMoa032922)

2 Polak M \& Cave H. Neonatal diabetes mellitus: a disease linked to multiple mechanisms. Orphanet Journal of Rare Diseases 2007212. (https://doi.org/10.1186/1750-1172-2-12)

3 Hattersley AT \& Ashcroft FM. Activating mutations in Kir 6.2 and neonatal diabetes new clinical syndromes, new scientific insights and new therapy. Diabetes $2005 \mathbf{5 4} 2503-2513$. (https://doi. org/10.2337/diabetes.54.9.2503)

4 Clement JP 4th, Kunjilwar K, Gonzalez G, Schwanstecher M, Panten U, Aguilar-Bryan L \& Bryan J. Association and stoichiometry of K(ATP) channel subunits. Neuron 199718 827-838. (https://doi. org/10.1016/s0896-6273(00)80321-9)

5 Sturgess NC, Ashford ML, Cook DL \& Hales CN. The sulphonylurea receptor may be an ATP-sensitive potassium channel. Lancet 19852 474-475. (https://doi.org/10.1016/s01406736(85)90403-9)

6 Abbasi F, Saba S, Ebrahim-Habibi A, Sayahpour FA, Amiri P, Larijani B \& Amoli MM. Detection of KCNJ11 gene mutations in a family with neonatal diabetes mellitus: implications for therapeutic management of family members with long-standing disease. Molecular Diagnosis and Therapy 201216 109-114. (https://doi. org/10.1007/bf03256435)

7 Støy J, Greeley SA, Paz VP, Ye H, Pastore AN, Skowron KB, Lipton RB, Cogen FR, Bell GI, Philipson LH, et al. Diagnosis and treatment of neonatal diabetes: a United States experience. Pediatric Diabetes 2008 9 450-459. (https://doi.org/10.1111/j.1399-5448.2008.00433.x) 8 Bonnefond A, Philippe J, Durand E, Dechaume A, Huyvaert M, Montagne L, Marre M, Balkau B, Fajardy I, Vambergue A, et al. Whole-exome sequencing and high throughput genotyping identified KCNJ11 as the thirteenth MODY gene. PLoS ONE 20127 e37423. (https://doi.org/10.1371/journal.pone.0037423)

9 Ellard S, Lango Allen H, De Franco E, Flanagan SE, Hysenaj G, Colclough K, Houghton JA, Shepherd M, Hattersley AT, Weedon MN, et al. Improved genetic testing for monogenic diabetes using targeted next-generation sequencing. Diabetologia 201356 1958-1963. (https://doi.org/10.1007/s00125-013-2962-5)

10 Pearson ER, Flechtner I, Niølstad PR, Malecki MT, Flanagan SE, Larkin B, Ashcroft FM, Klimes I, Codner E, Iotova V, et al. Switching from insulin to oral sulfonylureas in patients with diabetes due to Kir 6.2 mutations. New England Journal of Medicine 2006355 467-477. (https://doi.org/10.1056/NEJMoa061759)

11 Slingerland AS \& Hattersley AT. Mutations in the Kir 6.2 subunit of the $\mathrm{K}_{\text {ATP }}$ channel and permanent neonatal diabetes: new insights and new treatment. Annals of Medicine 200537 186-195. (https://doi. org/10.1080/07853890510007287)

Received in final form 26 January 2020

Accepted 7 February 2020 